\title{
MENSTRUATION AND THE BAR EXAM: UNCONSTITUTIONAL TAMPON BANS
}

\author{
BRIDGET J. CRAWFORD*
}

\section{Abstract}

Some states have policies that prevent bar exam candidates from bringing their own menstrual products to the test. Via social media, awareness of these policies achieved new heights in the weeks leading up to the July 2020 bar exam. A small number of jurisdictions responded to public criticism by permitting test takers to bring menstrual products with them to the exam, whether administered traditionally or remotely in response to the COVID-19 pandemic. Not all states have adopted permissive policies, however. This Essay explains why outright bans on menstrual products at the bar exam likely are unconstitutional. So-called alternate policies, such as making menstrual products available in women's restrooms, are inadequate. Only a "free-carry" policy for menstrual products is consistent with welcoming all qualified candidates to the legal profession, without regard to biology.

\section{INTRODUCTION}

Aspiring lawyers planning to take the bar exam during the coronavirus pandemic face considerable challenges. In the pandemic's early months, leading up to the July 2020 bar exam, candidates continued to study for a test that was not certain to occur. Just a few weeks before the original test dates, some states made late-breaking decisions to postpone or cancel their bar exams. ${ }^{1}$ In other jurisdictions where the test was scheduled to proceed as planned, another source of anxiety emerged. News spread on social media that some states banned bar candidates from bringing their own menstrual products to the examination. In response to public criticism, a small number of states modified their policies to expressly permit bar candidates to bring menstrual products, but not all states

\footnotetext{
*Bridget J. Crawford is a University Distinguished Professor and Professor of Law at the Elisabeth Haub School of Law at Pace University. For helpful comments and conversations, I thank Naomi Cahn, Elizabeth B. Cooper, Margaret E. Johnson, Marcy L. Karin, and Emily Gold Waldman.

${ }^{1}$ See, e.g., Karen Sloan, New York Cancels September Bar Exam Without an Alternative Test in Place, N.Y.L.J. (July 16, 2020), https://www.law.com/newyorklawjournal/2020/07/16/new-york-cancels-septemberbar-exam-without-alternative-test-in-place/ [https://perma.cc/2KPA-MWYL]; see also infra Part I.
} 
did so. ${ }^{2}$ Discrimination against menstruating bar-exam candidates persists in many jurisdictions in the United States.

Part I of this Essay provides an overview of states' policies on menstrual products leading up to the July 2020 bar exam administration. It then describes the social-media generated critique of those policies and the modifications that bar examiners made (or did not make) in response. Beyond the tampons referred to in the title of this Essay, all menstrual products - including tampons, pads, and menstrual cups - appear to be subject to bar examiners' policies. Part II outlines the argument that these bans on menstrual products at the bar exam are an unconstitutional form of gender discrimination. There are three potential problems with so-called alternative policies, such as providing products in women's restrooms or informally permitting candidates to bring menstrual products. These alternatives (1) do not meet the needs of all test takers; (2) promote uncertainty and confusion among bar candidates; and (3) evince a hostility toward approximately half of all future lawyers. The Essay concludes by linking access to menstrual products to other concerns that bar examiners must address in order to make testing conditions fair for all. Test administration policies should be consistent with the legal profession's greatest values of equal opportunity and inclusion.

\section{I. \#BloodyBarpocalypse: Some States Prohibit Menstrual Products at the Bar Exam}

In the Spring of 2020, when law schools in the United States pivoted abruptly to online instruction, no one could have foreseen that the pandemic would continue well into the next academic year. After the cancellation of in-person graduation ceremonies, recent law school graduates hunkered down to study for bar exams that were not certain to occur in July. Some states, such as Hawaii and North Dakota, cancelled their July exam administrations with ample notice to candidates. ${ }^{3}$ Other states like Illinois announced that it would proceed with the in-person exam as scheduled, only to cancel just five days before the test date in favor of a September in-person test that ultimately was cancelled as well. ${ }^{4}$

\footnotetext{
${ }^{2}$ See infra Part II.

${ }^{3}$ See, e.g., Which States Are Delaying the July 2020 Bar Exam and Offering a Fall Bar Exam Instead, JD ADVISING, https://www.jdadvising.com/which-states-are-delaying-the-july-2020-bar-exam/ [https://perma.cc/G76M-WYTE].

${ }^{4}$ See Information for Bar Exam Applicants, Ill. BD. OF AdMissions to the BAR (Nov. 1, 2020), https://www.ilbaradmissions.org/appinfo.action?id=1 [https://perma.cc/25TC-53B7].
} 
Amidst this unprecedented uncertainty, exam candidates took to social media to publicize that some state boards of bar examiners prohibit test takers from bringing menstrual products with them. No state has ever provided a rationale for this prohibition; presumably such a policy has something to do with unarticulated concerns about cheating or test security. ${ }^{5}$ Consider the example of Arizona, to name just one state. The administrators of the Arizona bar examination sent to July 2020 exam candidates a list of items "strictly prohibited" in the exam room. ${ }^{6}$ The list included predictable items, such as cell phones and backpacks, but also "feminine hygiene products," explaining that these "will be made available in the women's restrooms," but not giving a rationale for the prohibition on candidates' bringing their own menstrual products. ${ }^{7}$ After an outpouring of criticism — notably on Twitter under the hashtag \#bloodybarpocalypse originated by Professor Caitlin Moon ${ }^{8}$-Arizona wisely changed its policy. ${ }^{9}$ Shortly thereafter, Texas announced that it would change its policy for the September 2020 bar exam, ${ }^{10}$ but then did not alter its published instructions for October 2020 bar exam takers. ${ }^{11}$

By means of an open letter dated July 20, 2020 and signed by over 2,800 lawyers and law students in just twenty-four hours, Professors Marcy L. Karin, Margaret E. Johnson,

\footnotetext{
${ }^{5}$ See infra Part II.A. James Wollack, a professor of educational psychology at the University of Wisconsin, has speculated that prohibitions on access to menstrual products during the exam might be related to ease with which cameras, test answers, and earpieces can be hidden in everyday items. See Stephanie Francis Ward, Do Some States Really Prohibit Bringing Tampons and Pads to the Bar Exam? ABA J. (Jul. 23, 2020), https://www.abajournal.com/web/article/one-state-prohibits-bringing-tampons-and-pads-at-bar-exam-whileanother-retreats-on-its-position [https://perma.cc/AX9G-TRTK].
}

${ }^{6}$ Instructions and Information: Arizona Uniform Bar Examination July 28-29, 2020, SuP. Cт. STATE OF ARIZ., https://drive.google.com/file/d/1UcA158aOb1z-fIcv9GS8PIQ_a3q4w-cM/view [https://perma.cc/AC39-HENS].

${ }^{7} I d$.

8See Cat Moon (@inspiredcat), Twitter (Jul. 16, 2020, 5:27 PM)

https://twitter.com/inspiredcat/status/1286721655696502789 [https://perma.cc/K7RQ-Z2JJ].

${ }^{9}$ See Bridget J. Crawford \& Emily Gold Waldman, Tampons and Pads Should Be Allowed at the Bar Exam, N.Y.L.J. (July 22, 2020), https://www.law.com/newyorklawjournal/2020/07/22/tampons-and-pads-should-beallowed-at-the-bar-exam/ [https://perma.cc/XMF5-93LN] (reporting change in Arizona policy).

${ }^{10}$ See, e.g., Shannon Najmabadi, Texas Lifts Tampon Ban After Complaints Over Discriminatory Policy, TEX. TRIB. (Aug. 1, 2020) https://www.texastribune.org/2020/08/01/Texas-tampon-bar-exam/ [https://perma.cc/UNU6-QA6J].

${ }^{11}$ See Texas Bar Examination General Instructions October 5-6, 2020, TEX. BD. OF L. EXAM'RS, https://ble.texas.gov/bar-exam-general-instructions [https://perma.cc/P394-F96X]. 
and Elizabeth B. Cooper amplified and publicized concerns about state bar examiners' menstrual product policies. Their letter urged the National Conference of Bar Examiners (NCBE) to prohibit state bans on menstrual products. ${ }^{12}$ In response to the open letter, an NCBE spokesperson said the organization "had contacted all jurisdictions to clarify any misunderstanding about our policy and to let them know that we strongly discourage any prohibition on allowing candidates to bring their own menstrual products into the testing room," but the organization did not release any official policy. ${ }^{13}$ For months afterwards, Professors Karin, Johnson, and Cooper, collaborating under the umbrella advocacy group name "Menstrual Products and the Bar," worked with teams of law students from Fordham Law School's Legislative and Policy Advocacy Clinic and the University of the District of Columbia School of Law's Legislation/Civil Rights Clinic to reach out to bar examiners. The students urged states to issue clear, publicly-available guidance that expressly permits candidates to bring their own menstrual products to the bar exam; they also developed a model policy that states can adopt. ${ }^{14}$ This work continues with real-time updates delivered via social media, including the Twitter account @MPandtheBar. The advocacy has already met with some success. At its midyear meeting in 2021, the American Bar Association's House of Delegates adopted a resolution urging all bar admissions authorities to publish clear policies and rules that permit test takers to bring their own menstrual products to the bar exam in opaque containers. ${ }^{15}$

\footnotetext{
${ }^{12}$ Letter from Elizabeth B. Cooper, Margaret E. Johnson, Marcy L. Karin et al., to Judith Gundersen, Pres. \& CEO, NTL. CONF. OF BAR EXAM'Rs (Jul. 20, 2020), https://drive.google.com/file/d/1sbRQ6hpcvFO42sabh0aH_vCiA4jD9Rbv/view [https://perma.cc/727Z4ELV].
}

${ }^{13}$ Hailey Konnath, Allow Menstrual Products at the Bar Exam, Thousands Tell NCBE, LAw 360 (July 20, 2020), https://www.law360.com/legalindustry/articles/1293769/allow-menstrual-products-at-bar-examthousands-tell-ncbe [https://perma.cc/ELT2-VETT] (quoting NBCE representative Valerie Hickman).

${ }^{14}$ See Elizabeth B. Cooper, Margaret E. Johnson \& Marcy L. Karin, Menstrual Products and the Bar: Advocacy Seeks to Create Equal Bar Exam Testing Conditions for Menstruators, Best Practices For Legal Educ. (Aug. 5, 2020), https://bestpracticeslegaled.com/2020/08/05/menstrualproducts-and-the-bar-advocacy-seeks-to-create-equal-bar-exam-testing-conditions-formenstruators/\#MPandTheBar [https://perma.cc/KS8K-TCT8]; Elizabeth B. Cooper, Marcy L. Karin \& Margaret E. Johnson, Menstrual Dignity for Bar Examinees, 55 U.C. DAVIS L. REV. (forthcoming 2021) (manuscript at 54-59), https://ssrn.com/abstract=3790439 [https://perma.cc/67AZ-XPE7]_[hereinafter Menstrual Dignity].

${ }^{15}$ See Midyear Meeting 2021 House of Delegates Res. 105, Am. BAR Ass'N, https://www.americanbar.org/content/dam/aba/administrative/news/2021/02/midyear-resolutions/105.pdf [https://perma.cc/7QA6-2VA2]. 
In July 2020 , thirteen states ultimately went forward with the traditional two-day, inperson exam. ${ }^{16}$ Other jurisdictions responded in different ways including alternate test dates for in-person or remote exams (or a combination of both) ${ }^{17}$ total cancelation of the bar exam, ${ }^{18}$ and/or offering some form of diploma privilege. ${ }^{19}$ For those needing to address their own menstruation while taking the test, remote exam administrations were not trouble-free. For example, Maryland's October 2020 bar exam rules required takers to remain seated in front of their computer cameras for the full duration of each 90-minute testing session. ${ }^{20}$ One candidate who got her period in the middle of the exam made the decision to leave her seat to obtain a menstrual product instead of bleeding all over the chair. ${ }^{21}$ Via social media, the candidate later reported that she was disqualified by bar examiners for leaving the view of the camera during the test administration. ${ }^{22}$ The experience of this test-taker illustrates the importance of taking the biological fact of menstruation into account in designing all testing policies. Unless allowances are made for menstruation (to name just one biological process with relevance), not all candidates

\footnotetext{
${ }^{16}$ See July 2020 Bar Exam Status by Jurisdiction, NAT'L CONF. OF BAR EXAM'RS, https://www.ncbex.org/ncbe-covid-19-updates/july-2020-bar-exam-jurisdiction-information/statustable/ [https://perma.cc/9NT5-5GGX] (last updated Sept. 24, 2020) [hereinafter NBCE].

${ }^{17}$ See id.

${ }^{18}$ See July 2020 Bar Exam: Jurisdiction Information: Jurisdiction Announcements in Alphabetical Order, NBCE https://www.ncbex.org/ncbe-covid-19-updates/july-2020-bar-exam-jurisdictioninformation/\#Delaware [https://perma.cc/5N9Q-KL5Y].

${ }^{19} I d$.

${ }^{20}$ See Updated FAQs Related to the October 2020 Remote Bar Exam in Maryland, MD. CTS, (Sept. 18, 2020), https://www.mdcourts.gov/sites/default/files/import/ble/pdfs/october2020remotebarexamfaqs.pdf [https://perma.cc/DRV4-SN3K].

${ }^{21}$ Cecelia Scheeler (@CeciliaScheeler), TwiTter (Oct. 6, 2020, 12:40 PM), https://twitter.com/CeceliaScheeler/status/1313519480803405833 [https://perma.cc/V5QG-VYZL] (“Guess who got her period in the middle of the \#barexam and had to leave camera view for a few minutes or bleed all over her dad's really nice office chair? See y'all in February, I guess.").

22 Cecelia Scheeler (@CeciliaScheeler),TwiTTER (Dec. 3, 2020,5:54 PM), https://twitter.com/CeceliaScheeler/status/1334632068232437768 [https://perma.cc/299Q-F9FK] (“Got DQ'd for leaving camera view on \#barexam. See y'all in February.”) and Cecelia Scheeler (@CeciliaScheeler), TwitTER (Dec. 4, 2020, 11:45 PM), https://twitter.com/CeceliaScheeler/status/1334901563920424961 [https://perma.cc/MMD8-DXDY] ('I mean I don't think I would have passed anyway because the lack of scrap paper absolutely killed me (which is why I'm taking in person in Feb), but I'm still pissed it happened like this. \#barexam")).
} 
will have equal opportunities to succeed. ${ }^{23}$ Anything short of a "free-carry" policy for menstrual products will disadvantage approximately half of all future lawyers. Furthermore, as Professors Cooper, Karin, and Johnson have pointed out, a free-carry policy alone will not fully address menstruation-related concerns if candidates cannot address urgent menstrual needs because of prohibitions on leaving one's seat, except at designated break times. ${ }^{24}$ While recognizing that restroom access is a related problem that bar examiners must address, the next part of this Essay narrows its focus to the menstrual product bans themselves. It outlines possible constitutional objections to menstrual product bans and critiques some states' so-called alternate policies as inconsistent with the highest and best values of the legal profession.

\section{Menstrual Product Bans Are Unconstitutional and Substitute Policies Fail}

\section{A. Bans Are Unconstitutional}

In the context of the state sales tax, Professor Emily Waldman and I have developed the argument that taxes on menstrual products likely violate equal protection principles. ${ }^{25}$ Our argument applies similarly in the case of bar examiners' bans on menstrual products. ${ }^{26}$ To summarize briefly, a successful claim for gender discrimination under the Fourteenth Amendment requires a finding of both state action and discrimination on the basis of sex. In the case of the bar exam, there is clearly state action, because the board of bar examiners is an entity of the state. ${ }^{27}$ Sovereign immunity, which otherwise shields government officials from lawsuits for acting in their official capacities, does not apply when states or public officials violate federal or state constitutional rights. ${ }^{28}$ Therefore,

\footnotetext{
${ }^{23}$ Other biological conditions include lactation, for example. One bar candidate with a four-month old baby reportedly was denied an accommodation for breast pumping, on the grounds that the need was “not a medical condition.” LadyLawyerDiaries (@LadyLawyerDiary), TwiTTER (Jul. 21, 2020, 9:49 PM), https://twitter.com/LadyLawyerDiary/status/1285753864461967361 [https://perma.cc/Y5NL-N5NU].

${ }^{24}$ See Cooper, Karin \& Johnson, Menstrual Dignity, supra note 14 (manuscript at 30-35).

25 See Bridget J. Crawford \& Emily Gold Waldman, The Unconstitutional Tampon Tax, 53 U. RICH. L. REV. 439 (2019).

${ }^{26}$ See Crawford \& Waldman, supra note 9.

${ }^{27}$ See Anonymous v. Kaye, 987 F. Supp. 131 (1997) (recognizing the New York State Board of Law Examiners as an entity of the state).

${ }^{28}$ See, e.g., id.; Dep't of Revenue v. Kuhlien, 646 So.2d 717, 721 (Fla. 1994) (noting that "sovereign immunity does not exempt the State from a challenge based on violation of the federal or state constitutions").
} 
boards of bar examiners can be made party to a suit challenging the bans on menstrual products at the bar exam. In determining whether there is discrimination on the basis of sex, a court's inquiry depends on whether the challenged classification is gender neutral on its face. Facially neutral classifications are subject to a two-step inquiry: First, whether the classification is, in fact, based on gender; and second, whether the classification's disparate impact reflects "invidious gender-based discrimination." ${ }^{29}$ Facially sex-based classifications receive intermediate scrutiny, meaning that they must be substantially related to an important governmental purpose. ${ }^{30}$ Just as Professor Waldman and I have argued about state sales taxes on menstrual products, bar examiners' bans on menstrual products likely fail under either analysis. ${ }^{31}$

To be clear at the outset, bar examiners' bans on menstrual products are facially neutral as a linguistic matter. The policy applies equally to people of all genders. But because menstrual products are so closely associated with what historically has been called the "female" sex, these products function as a proxy for sex. Bans on menstrual products are bans on the basis of sex. ${ }^{32}$ Consider, for example, if a state's board of bar examiners were to ban a necessity such as eyeglasses. ${ }^{33}$ There is no doubt that people with poor eyesight would be impacted, without regard to gender. But menstrual product bans apply only those who menstruate. To be sure, menstruation is not unique to cis women. There are trans, gender non-binary, and genderqueer people who menstruate, as well as cis women who do not menstruate. ${ }^{34}$ But all who menstruate possess some portion of the biology associated with the "female" sex. ${ }^{35}$ The contemporary understanding of sex

\footnotetext{
${ }^{29}$ Personnel Administrator v. Feeney, 442 U.S. 256, 274 (1979).

${ }^{30}$ Craig v. Boren, 429 U.S. 190, 197 (1976).

${ }^{31}$ See Crawford \& Waldman, supra note 9.

${ }^{32}$ See Crawford \& Waldman, supra note 24 (developing more thoroughly the argument that sales taxes on menstrual products are taxes on the basis of sex).
}

${ }^{33}$ Cf. Frequently Asked Questions-Exam Applicants, W. VA. CTS., http://www.courtswv.gov/legalcommunity/Bd-of-Law/FAQs-Exam-Applicants.pdf [https://perma.cc/5RJC-SRB7].

${ }^{34}$ See GLAAD Media Reference Guide - Transgender, GLAAD, https://www.glaad.org/reference/transgender [https://perma.cc/6W4Q-EX93] (providing glossary of terms) and Sarah E. Frank, Queering Menstruation:

Trans and Non-Binary Identity and Body Politics, Soc. INQUIRY 1, 16 (Feb. 5, 2020), https://onlinelibrary.wiley.com/doi/pdf/10.1111/soin.12355 [https://perma.cc/EPS8-SNKP] (describing experiences of menstruation by individuals with diverse gender identities).

${ }^{35}$ See Margaret E. Johnson, Emily Gold Waldman \& Bridget J. Crawford, Title IX and Menstruation, 43 HARV. J. L. \& GENDER 225, 229 n.20 (2020). 
and gender is more capacious than the male/female binary, but for constitutional purposes, a ban on menstrual products - a necessity for approximately half the population for a large portions of their lives - is a sex-based ban. ${ }^{36}$

If menstrual products bans are sex-based classifications, then they are subject to intermediate scrutiny. In United States v. Virginia, Justice Ginsburg explained that this requires the state to show an "exceedingly persuasive" justification. ${ }^{37}$ No state has ever attempted publicly to offer an explanation for barring menstrual product bans at the bar exam. ${ }^{38}$ There simply is no justification. Any worry that candidates might write on menstrual products (or their wrappers) to cheat when visiting the bathroom reflects an ignorance about these products. As one Twitter user demonstrated, it is quite difficult to write the rule against perpetuities on a tampon. ${ }^{39}$ Menstrual products do not open like extra-long scrolls on which copious notes can be written. ${ }^{40}$ Furthermore, bans on menstrual products are not only misinformed; they also signal distrust and suspicion of menstruating test takers. Bans are unjustified.

Even if menstrual product bans are not recognized as sex-based classifications, they still do not pass constitutional muster. With facially neutral statutes, the analysis requires evidence of "invidious discrimination," meaning an intent to discriminate. ${ }^{41}$ Prior to July 2020 , it is unlikely that the failure of bar examiners to include menstrual products on lists of permitted necessities reflected any plot against menstruating test takers. But given the fact that public discussions of menstruation and menstrual products have traditionally

\footnotetext{
${ }^{36}$ See generally Bridget J. Crawford \& Emily Gold Waldman, Menstruation Matters: Challenging THE LAW's SILENCE ON PERIODS (forthcoming 2022) (discussing in Chapter 7 the importance of inclusive discussions about menstruation and the inadequacy of language, especially legal language, to capture adequately the full range of human experiences).

${ }^{37}$ U.S. v. Virginia, 518 U.S. 515, 531 (1996).

${ }^{38}$ See supra note 5 and accompanying text.

${ }^{39}$ LadyLawyerDiaries (@LadyLawyerDiary),TwitTer (July 17, 2020, 1:06 PM), https://twitter.com/LadyLawyerDiary/status/1284172658469462020 [https://perma.cc/D8QZ-VMB2].

${ }^{40}$ See Elizabeth Sepper (@1sepper), TwitTER (July 16, 2020, 4:20 PM), https://twitter.com/lsepper/status/1283858180053835778_https://perma.cc/6Z9S-BPX9] (tweeting GIF of a character from a Disney movie unrolling a comically long scroll under the heading "How Arizona bar examiners think tampons work").

${ }^{41}$ See Feeney, 442 U.S. 256.
} 
been the source of shame or disfavor, ${ }^{42}$ these bans should be understood as grounded in negative attitudes that fuel an "out of sight, out of mind" approach to menstruation. In other words, menstrual products will never make it onto a state's list of items expressly permitted at the exam unless those responsible for the policy feel comfortable mentioning them in the first place and including words like "tampons" and "menstrual pads" in official communications to bar exam candidates.

Note also that when Justice Scalia wrote in Bray v. Alexandria Women's Health Clinic that, "A tax on wearing yarmulkes is a tax on Jews," he was explaining how a facially neutral statute (such as one that applies to the wearing of yarmulkes by anyone, without regard to the religion of the wearer) that disfavors a particular activity can constitute invidious discrimination against a protected class (i.e., Jews, the predominant wearers of yarmulkes, although some members of the Catholic clergy also wear skullcaps). ${ }^{43}$ By analogy, menstrual product bans give rise to an inference of discriminatory intent because of the long history of treating menstruation with disfavor. ${ }^{44}$ From ancient times to the present, menstruation has been and is associated with uncleanliness, ${ }^{45}$ low social status, ${ }^{46}$ mental instability, ${ }^{47}$ and untrustworthiness, ${ }^{48}$ among other negative characteristics. So even if a ban on menstrual products is facially neutral,

\footnotetext{
${ }^{42}$ See Crawford \& Waldman, supra note 24, at 478-79 (describing taboos related to menstruation and menstrual products).

${ }^{43}$ Bray v. Alexandria Women's Health Clinic, 506 U.S. 263, 270 (1993).

${ }^{44}$ See, e.g., Bridget J. Crawford \& Emily Gold Waldman, Period Poverty in a Pandemic: Harnessing Law to Achieve Menstrual Equity, 98 WASH. U. L. ReV. 1569, 1589-92 (2021) (discussing several menstrual taboos that can be found in religious texts, secular literature, and contemporary cultural attitudes).

${ }^{45}$ See, e.g., Leviticus 15:19-22 (providing that a menstruating woman "shall remain in her impurity seven days; whoever touches her shall be unclean until evening ... and anyone who touches any object on which she has sat shall wash his clothes, bathe in water, and remain unclean until evening").
}

${ }^{46}$ See, e.g., Bridget J. Crawford \& Carla Spivack, Tampon Taxes, Discrimination \& Human Rights, 2017 WISC. L. REV. 491, 509-11 (discussing literary examples of menstruation, including the scene from Shakespeare's Merchant of Venice where Portia stabs herself in order to liken herself to men, who bleed after being wounded in combat, as opposed to women, who bleed involuntarily).

${ }^{47}$ See, e.g., Maria Luisa Marván et al., Stereotypes of Women in Different Stages of Reproductive Life: Data from Mexico and the United States, 29 Health CARE FOR Women InT'L 673, 679 (2008) (reporting the results of a study of 349 college students in the United States and Mexico asked to provide words associated with menstruating women, with results including 92 negative words such as "unpredictable" and "moody," but only 55 neutral words and 33 positive words).

${ }^{48}$ See, e.g., South Park: Bigger, Longer \& Uncut (Paramount Pictures 1999) (in which male character says to a female character, "I just don’t trust anything that bleeds for five days and doesn't die."). 
menstruation has long been the object of scorn and disdain. Because bar examiners permit other gender-neutral necessities, disfavoring necessities used only by persons with "female" biology constitutes invidious discrimination against a protected class. ${ }^{49}$

Prior to July 2020, a state's failure to adopt a "free-carry" policy for menstrual products probably reflected a lack of awareness about the products' importance or a general squeamishness about mentioning in public what some consider a "private" matter. Since July 2020, however, Professor Cooper's and Professor Karin's students have contacted every state board of bar examiners seeking information or clarification about their menstrual product policies. The American Bar Association's House of Delegates has recommended that test takers be able to bring their own menstrual products to the bar exam. ${ }^{50}$ Going forward, any jurisdiction's failure to adopt a free-carry policy cannot be excused as the result of unawareness; it tips even more blatantly into unconstitutional discrimination. ${ }^{51}$

\section{B. Substitute Policies Are Inadequate}

Just as some states prohibit bar candidates from bringing their own menstrual products to the exam, other states expressly permit these products. Still other states attempt to strike some compromise between those two approaches. They either adopt "shadow" (non-public) verbal policies that contradict written instructions provided to bar exam candidates or bar examiners promise to provide menstrual products during the bar exam. Some states do both. None of these "compromise" approaches is fair or adequate.

The shadow policy approach is best exemplified by West Virginia. The state's public rules for bar exam candidates do not include menstrual products on the list of the "only items allowed in the testing room.. ${ }^{, 2}$ Yet a spokesperson for the West Virginia courts has told the press that test takers may bring their own menstrual products to the exam in an opaque container. ${ }^{53}$ This permissive policy would not be public unless the press had

\footnotetext{
${ }^{49}$ See Emily Gold Waldman, Compared to What? Menstruation, Pregnancy, and the Complexities of Comparison, 41 COLUM. J. GENDER \& L. 218 (2021) (discussing the complexities of bringing discrimination claims in the case of pregnancy or menstruation, where there is no direct gender-neutral comparison).

${ }^{50}$ See supra note 15 and accompanying text.

${ }^{51}$ See supra note 14 and accompanying text.

${ }^{52}$ See supra note 33 and accompanying text.

${ }^{53}$ See Ward, supra note 5 (quoting Edythe Nash Gaiser, the West Virginia clerk of court).
} 
contacted the West Virginia Courts in response to social media criticism in July 2020. The work of Professors Cooper, Karin, and Johnson reveals that West Virginia is not alone in adopting a shadow policy, however. ${ }^{54}$ Some state boards of bar examiners have orally reported that, despite the failure to denominate menstrual products as "permitted" materials, these products nevertheless are permitted at the bar exam. ${ }^{55}$ Such shadowindeed secret - policies create uncertainty and confusion among bar candidates at a time when they should be focused on the exam itself. ${ }^{56}$ Curiously, in conjunction with its shadow policy, West Virginia also informs bar candidates that "feminine hygiene products" will be provided at the exam, but no details are available. ${ }^{57}$

States that promise to furnish menstrual products to test takers include Texas and Pennsylvania, in addition to West Virginia. The July 2020 bar exam instructions for both Texas and Pennsylvania provided that menstrual products would be available in the women's restrooms at exam sites..$^{58}$ As Professor Waldman, others, and I have articulated ${ }^{59}$ there are multiple problems with such variations on menstrual product bans. First, supplies may run out. Second, individuals have different needs when it comes to menstrual products; there is no such thing as a "one size fits all" product. Third, even if one product could meet all test takers' needs, unless menstrual products are available in all restrooms, trans, gender non-binary, and genderqueer test takers will not have equal access to them. Requiring test takers to search out menstrual products from proctors is not better; that may result in delays at best and harassment at worst. For example, a North Carolina test taker reported that at the July 2020 bar exam, when she complied with a bar official's request to show the contents of her clear plastic bag of personal items, the

\footnotetext{
${ }^{54}$ See Elizabeth B. Cooper, Margaret E. Johnson \& Marcy L. Karin, Menstrual Dignity, supra note 14 (manuscript at 16).

${ }^{55} \mathrm{Id}$.

${ }^{56}$ See Margaret E. Johnson, Marcy L. Karin \& Elizabeth B. Cooper, Stop the Stigma Against Menstruators; Starting with the Bar Exam, NAT'L JURIST (July 28, 2020, 3:31 PM), https://www.nationaljurist.com/nationaljurist-magazine/stop-stigma-against-menstruation-starting-bar-exam [https://perma.cc/357H-ZN4Y].

${ }^{57}$ See supra note 33 and accompanying text.

${ }^{58}$ See Elizabeth B. Cooper, Margaret E. Johnson \& Marcy L. Karin, Menstrual Dignity, supra note 14.

${ }^{59}$ See Bridget Crawford, Menstrual Equity and the Bar Exam: Round Up of Op-Eds and Other Media Coverage, Feminist L. Professors (Jul. 29, 2020), $\mathrm{http}$ ://www.feministlawprofessors.com/2020/07/menstrual-equity-and-the-bar-exam-round-up-of-op-eds-andother-media-coverage-bloodybarpocalypse/ [https://perma.cc/9S9E-N3SX].
} 
official asked of her menstrual products, "Do you really need these?"60 This type of harassment and shaming should never occur, but likely will continue in the absence of a free-carry policy for menstrual products.

States that do not allow test takers to bring their own menstrual products to the bar exam convey a message that approximately half of all future lawyers fall short of bar examiners' vision of an ideal candidate: someone who neither menstruates nor might menstruate during the exam, and certainly not someone who needs to address that menstruation in the manner of their choosing. If gender diversity in the legal profession is to be more than an empty promise, bar examiners must permit candidates to bring their own menstrual products to the bar exam.

\section{CONCLUSION}

At a time when bar examiners are asking test takers to sign liability waivers related to possible COVID-19 exposure, ${ }^{61}$ a focus on menstrual products may seem like a minor issue to some. But menstruation is a regular part of life for roughly half of all exam takers. Failing to take menstruation into account in preparing lists of items permitted at the exam likely is a constitutional violation; it has significant practical consequences for menstruating bar candidates, too. To be sure, boards of bar examiners need policies that address in a fair manner all biologically-based needs, including those related to pregnancy and lactation, as well as candidates' specific medication needs. There is ample anecdotal evidence to suggest that existing policies are not sufficiently expansive. ${ }^{62}$ Fairly accounting for the biological needs of test takers during the bar exam is a cornerstone of a more inclusive legal profession. Increasing gender (and other) diversity in the bar favorably increases public confidence in the fairness of the legal system itself. ${ }^{63}$ Given what is at stake, then, all jurisdictions should adopt a free-carry policy for menstrual products at the bar exam.

\footnotetext{
${ }^{60}$ Britni C. Prybol (@BPrybol), TwiTter (July 30,2020, 8:43 PM), https://twitter.com/BPrybol/status/1288998671183486977 [https://perma.cc/VT8F-YF85].

${ }^{61}$ See, e.g., Jimmie E. Gates, July Bar Exam in Mississippi Amid Coronavirus Pandemic Requires Waiver of Liability, Miss. Clarion Ledger (Jul. 17, 2020), https://www.clarionledger.com/story/news/2020/07/17/mississippi-bar-exam-amid-covid-applicants-mustsign-waiver/5442243002 [https://perma.cc/N2ZW-K888].

${ }^{62}$ See, e.g., supra note 23 and accompanying text.

${ }^{63}$ See, e.g., Why Diversity Matters, Ill. State Bar Ass'N Diversity Council Newsl. (Jun. 2008), https://www.isba.org/committees/diversityleadershipcouncil/newsletter/2008/06/whydiversitymatters [https://perma.cc/C9RV-MQCC].
} 